\title{
Enough warheads, already
}

\author{
Its official: the reliability of existing US nuclear warheads makes their replacement unnecessary.
}

T his week, UK prime minister Tony Blair declared his intention to replace the Trident submarine fleet that carries Britain's nuclear weapons. His declaration has sparked a debate in Britain about the role of nuclear weapons in the modern world - and about the obligation of states with nuclear weapons to move towards disarmament under the 1968 Nuclear Non-Proliferation Treaty (NPT).

But as Britain ponders its submarines, the United States is conducting a lower-profile but even more fundamental debate on whether to replace the nuclear warheads themselves. Over the past five years, some US weapons specialists have pushed a variety of new weapons concepts. But since the end of the cold war, making the case for brand new nuclear weapons has, thankfully, been a tough sell.

In Congress, liberals tend to argue that such weapons would defy the NPT. Conservatives see them as overly expensive. The military is happy with the nuclear weapons it already has, and the president, like his predecessors, wishes to continue a voluntary moratorium on nuclear testing.

But supporters of new and improved nuclear weapons are nothing if not tenacious. These days their main vehicle is a proposed project to build a Reliable Replacement Warhead (RRW). The argument for its pursuit goes, taking the words in reverse order, like this. It is a warhead, so it would require the nuclear-weapons labs to bring their collective knowledge to bear on its design and production. But it is merely a replacement, not a new design, so it won't violate international obligations, and won't, it is said, require full testing. And it is reliable - the clear implication being that existing warheads are not, or will not be in the near future.

It was this last argument that gave some urgency to the RRW programme. When the idea was conceived, it was estimated that the plutonium 'triggers' that fire the existing nuclear warheads might last only $40-60$ years. As most of them are already 20 years old, it could be argued, it was time for the laboratories to start work right away on finding a reliable replacement.

Unfortunately for advocates of the programme, however, it has emerged that existing warheads are more reliable than envisaged. Last week, the US National Nuclear Security Administration, which manages the nuclear-weapons programme, released unclassified summaries of two studies that found that the existing plutonium triggers will last for up to a century (see page 660). And that's in the worst case - the triggers may well last even longer.

Advocates of the replacement programme inside the Bush administration are apparently undaunted. Speaking through the Nuclear Weapons Council, which comprises the leaders of the agencies in the federal government that have an interest in these matters, they argued that the principal role of the RRW would, in fact, be to augment the security and safety of existing warheads. But these things are already more than adequately assured, through the decade-old stockpile stewardship programme.

Even before the new studies were released, the RRW seemed to be stuck in Congress. With Democrat gains in last month's mid-term elections, its prospects are bleaker still. Already, two senators, Jeff Bingaman (Democrat, New Mexico) and Dianne Feinstein (Democrat, California), have made their opposition to the programme clear. The political will to pursue it simply isn't there.

That's just as well. No convincing case has been made for the United States to replace its existing nuclear warheads. Their dreadful function is dependent on principles that were proven 50 years ago and aren't going to change any time soon. The government should give up its desire for new designs and settle on a size and shape for a research programme that fits the less extravagant needs of its existing nuclearweapons stockpile - a stockpile that, with luck, will become obsolete before it needs to be replaced.

\section{A fair share}

\section{The concept of sharing primary data is generating unnecessary angst in the psychology community.}

$\mathrm{n}$ psychology there is little tradition of making the data on which researchers base their statistical analyses freely available to others after publication. This makes it difficult for anyone to independently reanalyse research results, and prevents small data sets from being combined for meta-analysis, or large ones mined for fresh insights or perspectives.

Psychologists need to rethink their reluctance to share data. Their discipline is 'softer' than some others: rarely do data on issues such as playground bullying or the usefulness of psychotherapy reveal really clear-cut answers. This makes the rigour with which the data are handled fundamental to research outcomes - and increases the desirability of having them open to examination by peers.

The need for more data sharing has just been amply demonstrated by Jelte Wicherts, a psychologist specializing in research methods at the University of Amsterdam, who tried to check out the robustness of statistical analyses in papers published in top psychology journals.

He selected the November and December 2004 issues of four journals published by the American Psychological Association (APA), which requires its authors to agree to share their data with other researchers after publication. In June 2005, Wicherts wrote to each corresponding author requesting data, in full confidence, for simple reanalysis. Six months and several hundred e-mails later, he abandoned the mission, having received only a quarter of the data sets. He reported his failure in an APA journal in October (J.M. Wicherts et al. Am. Psychol. 61, 726-728; 2006).

Researchers often have valid reasons for constraining access to their 